\title{
Medical comorbidities in patients with serious mental illness: a retrospective study of mental health patients attending an outpatient clinic in Qatar
}

Monica Zolezzi'

Sara Abdulrhim²

Nour Isleem ${ }^{2}$

Farah Zahrah ${ }^{2}$

Yassin Eltorki ${ }^{3}$

'Clinical Pharmacy and Practice, ${ }^{2}$ College of Pharmacy, Qatar

University, ${ }^{3}$ Department of Pharmacy, Hamad Medical Corporation Mental

Health Hospital, Doha, Qatar
Correspondence: Monica Zolezzi Clinical Pharmacy and Practice,

College of Pharmacy, Qatar University, PO Box 2730, Doha, Qatar

Tel +974 44035623

Fax +974 4403555 I

Email mzolezzi@qu.edu.qa
This article was published in the following Dove Press journal:

Neuropsychiatric Disease and Treatment

15 September 2017

Number of times this article has been viewed

Background: The life span of individuals with serious mental illness (SMI) is shorter compared to the general population. This excess mortality is mainly due to physical illness. The aim of the study was to investigate the prevalence rates of different physical illnesses in individuals with SMI and to examine how these are being managed.

Methods: The study was a cross-sectional retrospective chart review of a cohort of patients with SMI. A comprehensive electronic data extraction tool using SurveyMonkey ${ }^{\circledR}$ was used to collect patient demographics, psychiatric and medical comorbidities, medications and all relevant physical assessments. Data were then first extrapolated into an Excel ${ }^{\circledR}$ spreadsheet and later to SPSS $^{\circledR}$ for data analysis. A descriptive statistical approach was used to analyze the demographic and clinical data. Chi-square test for categorical variables and $t$-test for continuous variables were used to compare the demographic and clinical characteristics of the cohort.

Results: A total of 336 patients with SMI were included for the retrospective chart review. The majority of these patients had a diagnosis of depression $(50.3 \%)$, followed by schizophrenia (33.0\%) and bipolar disorder (19.6\%). Diabetes was the most frequent medical comorbidity, diagnosed in $16.1 \%$ of SMI patients, followed by hypertension $(9.2 \%)$ and dyslipidemia $(9.8 \%)$. Monitoring of comorbidity-associated risk factors and other relevant physical assessment parameters (such as blood pressure, weight, hemoglobin A1c [HbA1c], blood glucose and lipids) were documented in less than $50 \%$ of patients, and some parameters, such as smoking status, were not documented at all.

Conclusion: Both, the literature and our cohort provide evidence that individuals with SMI are less likely to receive standard levels of care for their medical comorbidities.

Keywords: serious mental illness, medical comorbidities, physical illness, psychiatric patients

\section{Introduction}

Numerous studies worldwide have reported disproportionate medical comorbidities and premature death among people with serious mental illness (SMI). ${ }^{1,2}$ SMI is generally defined as mental or behavioral disorders that result in significant functional impairment and limit an individual's ability to perform one or more major life activities. ${ }^{3}$ These disorders include schizophrenia, schizophrenia-like psychosis (eg, schizoaffective disorder), major depressive disorder (MDD) and bipolar affective disorder (BPAD). In some studies, the life expectancy of people with an SMI is estimated to be as much as 30 years less than in the general population. ${ }^{2,45}$ Several studies have attributed medical comorbidities among psychiatric patients as responsible for the premature 
death observed in this population..$^{5-7}$ Heart disease, cancer, respiratory conditions and metabolic disorders such as obesity and diabetes are among the most commonly underlying causes of mortality in patients with SMI. ${ }^{1,5-9}$ Contributing to the high prevalence of medical comorbidity in this population is the increased risk of weight gain associated with the majority of medications that are required to treat SMI, particularly with the newer atypical antipsychotics. ${ }^{10}$ Clinical research has shown a significant association between the use of atypical antipsychotic medication with the development of metabolic complications, which in turn may be contributing to the increased cardiovascular mortality seen in this patient population. ${ }^{11}$

In addition to this mortality and morbidity gap, there is increasing evidence that disparities exist in the medical care provided to individuals with SMI. The literature indicates that people with mental illnesses are less likely to receive the same level of medical services such as physical examinations or evidence-based medications for chronic medical conditions, and are more likely to perceive barriers to care than persons without mental illness. ${ }^{1,12-19}$ Various factors may contribute to the gap in medical care provided to patients with SMI, such as socioeconomic disadvantages, poor insight and unhealthy lifestyle choices (such as smoking, substance abuse, unbalanced diets and physical inactivity). ${ }^{8,14,20}$ Studies also suggest that the stigma associated with mental illness, which is also related to patient/provider/system barriers, prevents proper follow-up of patients with SMI once they are discharged from acute care into their communities, placing them at risk not only of mental health relapse but also for not having proper medical care. ${ }^{19,21}$

Although these health disparities have been well studied and addressed in the Western world, gaps in information on this issue still exist in the Arab world, particularly in Qatar. One of Qatar's national health strategies focuses on mental health and intends to develop programs to improve the delivery of mental health services that revolve around community-based care. ${ }^{22}$ The National Mental Health Strategy (NMHS) is a comprehensive response to address the mental health needs of people in Qatar that has resulted from research undertaken in this country that estimates that one in five people experiences a mental illness at any one time, but that less than $25 \%$ of those who need mental health services are accessing them. The NMHS also highlights findings from local studies that found that the level of mental health knowledge is low and that negative perceptions about mental illness cause people to delay or avoid seeking help.
Exploring the prevalence of medical comorbidities in people with mental illness and how these are being addressed are necessary to build strategies within the primary health care system to close the care gaps that have been highlighted in the NMHS. As such, the main goal of this project is to have a better understanding of the prevalence of medical comorbidities among a cohort of people with SMI attending an outpatient psychiatric clinic in Qatar and how these medical comorbidities are being managed.

\section{Methods}

A retrospective chart review of a cohort of patients living in the community for at least 1 year and attending an outpatient psychiatric clinic for follow-up was conducted. Ethical approval for the study was granted by the Institutional Review Board (IRB) of Qatar University (reference number: QU-IRB 501-E/15) and by Hamad Medical Corporation (HMC) Medical Research Center (MRC) (reference number: MRC 1526/2016). Patients' consent to review their medical records was exempted by HMC MRC IRB as the research involved the collection of existing data and recorded in such a manner that subjects could not be identified, directly or through identifiers linked to the subjects, such as name, address, phone number, health plan number, medical record number, social security number or driver license number.

\section{Setting}

The study was conducted at the psychiatric outpatient clinic of HMC, located in Doha, Qatar. HMC is the largest provider of psychiatric services in the country. ${ }^{22}$ The HMC outpatient clinic manages an average of 50 visits per day, including walk-ins and referrals. Patients seen in the clinic include those who have been discharged from the psychiatric hospital and who are scheduled for follow-up appointments and treatment as well as those who are referred from primary health care clinics or private doctors.

\section{Sample}

All patients attending the psychiatric outpatient clinic between April 2015 and April 2016 were eligible to be included in the study. Those with an established diagnosis of SMI, including schizophrenia, MDD, BPAD and schizoaffective disorder (as per the Diagnostic and Statistical Manual of Mental Disorder, Fourth and Fifth Editions $)^{23}$ and not hospitalized at the psychiatric facility within the previous year, were suitable for inclusion for the retrospective chart review of their medical comorbidities, 
physical assessments and the associated treatments received. Based on the recommendation for estimating a sample size for retrospective chart reviews, and considering a 3-month data collection time frame, a sample size of 350 patient charts was targeted. ${ }^{24}$

\section{Data collection}

Using HMC electronic records, the medical charts of eligible patients attending the psychiatric outpatient clinic were reviewed from May to July 2016. Cerner ${ }^{\circledR}$ is the electronic medical record system used at HMC. The medical records contain all health and relevant demographic information (such as sociodemographics, allergy history, vital signs, laboratory test and imaging, vaccination, medication history, health care professionals medical notes, admission and discharge history and referrals) of all patients at every patient encounter with HMC services. A comprehensive electronic data extraction tool using SurveyMonkey ${ }^{\circledR}$ was used to collect patient demographics, psychiatric and medical comorbidities, medications and all relevant physical and laboratory assessments and treatments the eligible patients received within 1 year of the time the outpatient clinic visit took place. Earlier data on these parameters were not included in the study.

\section{Data analysis}

Data were then first exported into an Excel ${ }^{\circledR}$ spreadsheet and later to $\mathrm{SPSS}^{\circledR}$ for data analysis. A descriptive statistical approach was used to analyze the demographic and clinical data. Chi-square test for categorical variables and $t$-test for continuous variables were used to compare the demographic and clinical characteristics of the cohort. One-way analysis of variance was used to test for differences between categorical and continuous-type variables.

\section{Results}

The medical charts of a total of 336 outpatients were eligible for inclusion in the study. The summary of the cohort's characteristics is provided in Table 1. The mean age of the patients in the sample was $41.2 \pm 12.4$ (range: $15-80$ years of age); the majority (55.4\%) were females $(55.4 \%)$ and non-Qataris $(60.7 \%)$. The most prevalent SMI in this cohort was MDD (48.5\%). Almost a third of the cohort (29.2\%) had at least one medical comorbidity documented $(17.6 \%$ had one, $7.1 \%$ had two, $3.9 \%$ had three and $0.6 \%$ had up to four medical comorbidities). The most prevalent medical comorbidity was diabetes $(16.1 \%)$. The majority of patients $(65.2 \%)$ were on antipsychotics.
Table I Sample characteristics

\begin{tabular}{|c|c|}
\hline Characteristics & Sample $(n=336)$ \\
\hline Mean age, (years) $\pm S D$ & $41.2 \pm 12.4$ \\
\hline Female, n (\%) & $186(55.4)$ \\
\hline Male, n (\%) & $150(44.6)$ \\
\hline \multicolumn{2}{|l|}{ Nationality, n (\%) } \\
\hline Qatari & $132(39.3)$ \\
\hline Non-Qatari & $204(60.7)$ \\
\hline \multicolumn{2}{|l|}{ Psychiatric diagnosis, $\mathrm{n}(\%)$} \\
\hline MDD & $163(48.5)$ \\
\hline $\begin{array}{l}\text { Psychotic disorder (schizophrenia/ } \\
\text { schizoaffective disorder) }\end{array}$ & $103(30.7)$ \\
\hline BPAD & $61(18.2)$ \\
\hline Comorbid psychotic disorder and MDD & $7(2.1)$ \\
\hline Comorbid psychotic disorder and BPAD & $2(0.6)$ \\
\hline \multicolumn{2}{|l|}{ Medical comorbidities, n (\%) } \\
\hline Diabetes mellitus & $54(16.1)$ \\
\hline Hypertension & $31(9.2)$ \\
\hline Hyperlipidemia & $33(9.8)$ \\
\hline Thyroid abnormality & $20(6.0)$ \\
\hline Other medical comorbidities ${ }^{a}$ & $38(11.3)$ \\
\hline \multicolumn{2}{|l|}{ Psychiatric medications, n (\%) } \\
\hline Antidepressants & $215(64.0)$ \\
\hline Antipsychotics & $219(65.2)$ \\
\hline Mood stabilizers & $46(13.7)$ \\
\hline
\end{tabular}

Note: aOther comorbidities (coronary artery disease, respiratory diseases, osteoporosis, erectile dysfunction).

Abbreviations: MDD, major depressive disorder; BPAD, bipolar affective disorder; $\mathrm{SD}$, standard deviation.

As summarized in Table 2, the prevalence of diabetes was highest among those with psychotic disorders (21.4\%); hypertension was highest among those with MDD (10.4\%) and hyperlipidemia was highest among those with BPAD (13.1\%). However, the prevalence of the various medical comorbidities was not significantly different among patients with different types of SMI (all $p$-values were $>0.05$ ). As shown in Table 3, the mean age of SMI patients with comorbid medical conditions such as diabetes, hypertension, and dyslipidemia - but not thyroid disorders - was significantly higher than the mean age of SMI patients without comorbid medical conditions.

As illustrated in Figure 1, blood glucose was the most frequently monitored medical parameter in the cohort of

Table 2 Medical comorbidities among patients with different SMI

\begin{tabular}{lllll}
\hline Medical comorbidity & MDD & $\begin{array}{l}\text { Psychotic } \\
\text { disorder }\end{array}$ & BPAD & p-value \\
\hline Diabetes mellitus, n (\%) & $20(12.3)$ & $22(21.4)$ & $10(16.4)$ & 0.23 \\
Hypertension, n (\%) & $17(10.4)$ & $9(8.7)$ & $5(8.2)$ & 0.86 \\
Hyperlipidemia, n (\%) & $12(7.4)$ & $12(11.7)$ & $8(13.1)$ & 0.16 \\
Thyroid abnormality, n (\%) & $9(5.5)$ & $7(6.8)$ & $3(4.9)$ & 0.10 \\
Other comorbidities, n (\%) & $17(10.4)$ & $12(11.7)$ & $7(11.5)$ & 0.40 \\
\hline
\end{tabular}

Abbreviations: SMI, serious mental illness; MDD, major depressive disorder BPAD, bipolar affective disorder. 
Table 3 Age correlates of comorbidities among SMI patients

\begin{tabular}{|c|c|c|c|}
\hline $\begin{array}{l}\text { Medical } \\
\text { comorbidity }\end{array}$ & $\begin{array}{l}\text { Mean age }( \pm S D) \\
\text { of SMI patients } \\
\text { with comorbidity }\end{array}$ & $\begin{array}{l}\text { Mean age }( \pm S D) \\
\text { of SMI patients } \\
\text { without comorbidity }\end{array}$ & $p$-value \\
\hline Diabetes & $48.87 \pm 12.49$ & $39.73 \pm 11.84$ & $<0.01$ \\
\hline Hypertension & $52.06 \pm 11.92$ & $40.10 \pm 11.91$ & $<0.01$ \\
\hline Dyslipidemia & $48.82 \pm 9.40$ & $40.37 \pm 12.40$ & $<0.01$ \\
\hline $\begin{array}{l}\text { Thyroid } \\
\text { abnormality }\end{array}$ & $43.00 \pm 8.95$ & $41.09 \pm 12.58$ & 0.50 \\
\hline
\end{tabular}

Abbreviations: SMI, serious mental illness; SD, standard deviation.

patients with SMI (52.5\%). As summarized in Table 4, in patients with comorbid diabetes ( $\mathrm{n}=54)$, a blood glucose or a HbA1c test within the previous year was documented for $53.7 \%$ of patients. The second most frequently monitored parameter was blood cholesterol, documented in $48.5 \%$ of patients with SMI. Among those with comorbid hyperlipidemia $(n=33)$, lipids were documented for the majority of patients $(62.5 \%)$. Only $26.5 \%$ of patients had their blood pressure documented within the previous year. In patients with comorbid hypertension ( $\mathrm{n}=31)$, only $22.6 \%$ had their blood pressure documented within the previous year. Other medical parameters such as prolactin, weight and height were infrequently documented, and some, such as smoking history, were not documented at all.

As illustrated in Table 5, the majority of patients were on an antipsychotic ( $\mathrm{n}=219$ or $65.2 \%$ of the sample), of which 37 patients (16.9\%) also had comorbid diabetes, $11.4 \%$ comorbid hyperlipidemia, 9.6\% comorbid hypertension and $7.3 \%$ a comorbid thyroid disorder. Diabetes was also the most prevalent comorbidity among those on antidepressants ( 31 out of 215 , or $14.4 \%$ ) and among those on mood stabilizers ( 8 out of 46 , or $17.4 \%$ ).

There was no significant difference in glucose monitoring among those patients on antipsychotics versus those not on antipsychotic medications ( $50.7 \%$ vs $49.3 \%, p=0.19)$.

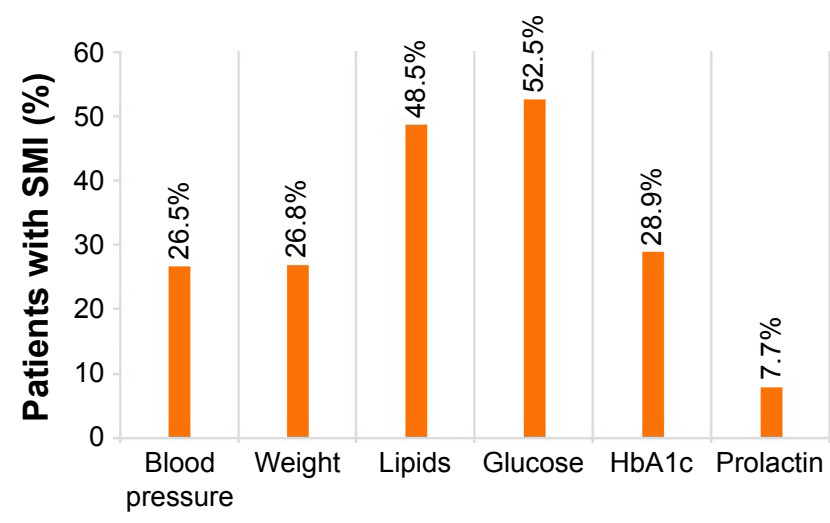

Figure I Physical health monitoring among the sample of patients with SMI. Abbreviations: SMI, serious mental illness; HbAlc, Haemoglobin Alc.
Table 4 Monitoring of medical comorbidities

\begin{tabular}{lll}
\hline $\begin{array}{l}\text { Monitoring parameters } \\
\text { performed within the last } \\
\text { year for patients with: }\end{array}$ & $\begin{array}{l}\text { Patients } \\
\text { monitored } \\
\text { (\%) }\end{array}$ & $\begin{array}{l}\text { Patients not } \\
\text { monitored } \\
\text { (\%) }\end{array}$ \\
\hline $\begin{array}{l}\text { Diabetes mellitus }(\mathrm{n}=54) \\
\text { Blood glucose/HbAIc, } \mathrm{n}(\%)\end{array}$ & $29(53.7)$ & $25(46.3)$ \\
$\begin{array}{l}\text { Patients on antipsychotic } \\
\text { medication ( } \mathrm{n}=2 \text { I9) } \\
\quad \text { Blood glucose, } \mathrm{n}(\%)\end{array}$ & $\mathrm{III}(50.7)$ & $108(49.3)$ \\
$\begin{array}{l}\text { Hypertension }(\mathrm{n}=3 \mathrm{I}) \\
\text { Blood pressure, } \mathrm{n}(\%)\end{array}$ & $7(22.6)$ & $24(77.4)$ \\
$\begin{array}{l}\text { Hyperlipidemia }(\mathrm{n}=32) \\
\text { Lipid panel, } \mathrm{n}(\%)\end{array}$ & $20(62.5)$ & $12(37.5)$ \\
\hline
\end{tabular}

Abbreviation: HbAIc, hemoglobin Alc.

Table 6 summarizes the psychiatric disorders and the medical comorbidities among Qataris versus non-Qataris with SMI. Qataris had a significantly higher prevalence of diabetes and hyperlipidemia than non-Qataris (diabetes $22.7 \%$ vs $11.8 \%, p<0.01$; hyperlipidemia $15.9 \%$ vs $5.9 \%$, $p<0.01)$. No significant differences in the monitoring parameters of medical comorbidities were found among Qataris versus non-Qataris.

\section{Discussion}

This study represents the first in Qatar to explore prevalence rates of concurrent medical comorbidity in a cohort of psychiatric patients with SMI. Roughly one-third of these patients $(29.2 \%)$ had at least one medical comorbidity. Other studies have found higher prevalence rates of medical comorbidity among patients with SMI. In a prospective study in India, Singh et al found that $48 \%$ of psychiatric outpatients had concurrent physical illnesses. ${ }^{25}$ A very similar medical comorbidity rate of $49 \%$ was reported by Manuel et al among a cohort of patients with psychiatric disorders admitted to hospital in Mangalore. ${ }^{26}$ The lower rates in our sample may be explained by the retrospective methodology used in our study. In both studies by Singh et al and Manuel et al, medical comorbidities were assessed prospectively, using a quick history checklist, physical examination and laboratory investigations, all of which aid in detecting common physical illnesses more accurately. Our sample of SMI patients with medical comorbidities was older than those without medical comorbidities. These patterns of age-related medical comorbidities are consistent with current literature regarding diabetes, hypertension and the components of the metabolic syndrome, such as dyslipidemia, in the general population in Qatar. ${ }^{27-30}$

In our sample, patients with BPAD had the highest prevalence of medical comorbidity (38\%). However, we found no statistically significant differences in the prevalence of medical comorbidities among patients with the three major 
Table 5 Psychiatric medications used in the sample of patients with SMI

\begin{tabular}{lllll}
\hline Medication/disease & Diabetes mellitus & Hyperlipidemia & Hypertension & Thyroid disease \\
\hline Antipsychotic $(65.2 \%, \mathrm{n}=219)$ & $16.9 \%$ & $11.4 \%$ & $9.6 \%$ & $7.3 \%$ \\
Antidepressant $(64 \%, \mathrm{n}=215)$ & $14.4 \%$ & $9.3 \%$ & $9.3 \%$ & $5.6 \%$ \\
Mood stabilizer (13.7\%, $\mathrm{n}=46)$ & $17.4 \%$ & $1.5 \%$ & $13 \%$ & $6.5 \%$ \\
\hline
\end{tabular}

Abbreviation: SMI, serious mental illness.

psychiatric disorders (psychotic disorders, BPAD and MDD). Again, it is possible that differences between these diagnostic groups may have been obscured by the retrospective nature of our data collection. Similar findings were also reported by Sokal et al in their study of medical comorbidities among individuals with SMI who were receiving community-based psychiatric treatment in Maryland, USA. ${ }^{31}$ They did not find any statistical differences either, even using a prospective data collection and after controlling for age, sex, race, education and socioeconomic status of the studied patients.

In line with other international studies, diabetes was the most prevalent medical comorbidity among our cohort of outpatients with SMI (16.1\%). A report derived from claims data of the US National Medicaid database, showed that more than half of disabled Medicaid enrollees with psychiatric conditions also had claims for diabetes, cardiovascular disease or pulmonary disease..$^{32}$ These rates were substantially higher than the rates of these illnesses among persons without psychiatric conditions. In our study, patients with psychotic disorders had the highest documented prevalence of diabetes (21.4\%) compared to those with BPAD (16.4\%) or with MDD (12.3\%), although we did not find statistically

Table 6 Differences among Qataris versus non-Qataris

\begin{tabular}{|c|c|c|c|}
\hline Demographics & $\begin{array}{l}\text { Qataris } \\
(n=132)\end{array}$ & $\begin{array}{l}\text { Non-Qataris } \\
(n=204)\end{array}$ & $p$-value \\
\hline Mean age (years) $\pm S D$ & $42.95 \pm 12.55$ & $40.06 \pm 12.18$ & 0.04 \\
\hline \multicolumn{4}{|l|}{ Sex } \\
\hline Male, n (\%) & $6 \mathrm{I}(46.2 \%)$ & 89 (43.6\%) & 0.64 \\
\hline Female, n (\%) & 7I (53.8\%) & II 5 (56.4\%) & \\
\hline \multicolumn{4}{|l|}{ Psychiatric disorder } \\
\hline Major depressive disorder & 49 (37.I\%) & $120(58.8 \%)$ & $<0.01$ \\
\hline Psychotic disorder & $62(47.0 \%)$ & 49 (24.0\%) & $<0.01$ \\
\hline Bipolar affective disorder & $27(20.5 \%)$ & 39 (19.1\%) & 0.43 \\
\hline \multicolumn{4}{|l|}{ Comorbidities } \\
\hline Diabetes & $30(22.7 \%)$ & $24(11.8 \%)$ & $<0.01$ \\
\hline Hypertension & $15(7.8 \%)$ & $16(11.4 \%)$ & 0.19 \\
\hline Hyperlipidemia & 21 (I5.9\%) & $12(5.9 \%)$ & $<0.01$ \\
\hline Thyroid disorder & $5(3.8 \%)$ & I5 (7.4\%) & 0.13 \\
\hline \multicolumn{4}{|l|}{ Monitoring parameters } \\
\hline Hemoglobin Alc & 37 (28.0\%) & $60(29.4 \%)$ & 0.44 \\
\hline Blood glucose & $63(47.7 \%)$ & 114 (55.9\%) & 0.09 \\
\hline Blood pressure & 37 (28.0\%) & $52(25.5 \%)$ & 0.35 \\
\hline Lipid panel & $60(45.5 \%)$ & $103(50.7 \%)$ & 0.20 \\
\hline Prolactin level & $8(6.1 \%)$ & I8 (8.8\%) & 0.24 \\
\hline
\end{tabular}

Abbreviation: SD, standard deviation. significant differences in the diabetes prevalence among patients grouped by SMI diagnoses. There are numerous studies that have shown that patients with schizophrenia are at two fold increased risk for diabetes compared to the general population. ${ }^{1,31,33,34}$ The prevalence rate for diabetes found in our study population diagnosed with psychotic disorders is considerably higher than that reported in other studies, even in those following a more rigorous prospective data collection methodology. ${ }^{25,26,35}$ The reason for the increased risk of diabetes among our study population is likely multifactorial, possibly related to effects of the medications used by people with SMI (65.2\% of our sample were on antipsychotics, of which $16.9 \%$ were diabetics) and also possibly related to the high prevalence of the metabolic syndrome in Qatar. In a study by Musallam et al, a crude prevalence rate of $34 \%$ according to the International Diabetes Federation criteria for diagnosing metabolic syndrome was found. ${ }^{29}$ The authors explained that the high prevalence of metabolic syndrome in Qatar compared to Western countries (reported to be approximately $20 \%-25 \%$ in the general population in the $\mathrm{US}^{36}$ ) could be due to genetic and environmental factors such as obesity, sedentary lifestyle and dietary habits., ${ }^{1,29}$ Unfortunately, we were not able to estimate the prevalence of the metabolic syndrome in our population due to poor documentation in weight, height and body mass index. Our results do show that there was a statistically significant difference in ages between Qataris and non-Qataris. As higher mean age is significantly associated with the presence of all medical comorbidities in our sample of SMI patients (with the exception of thyroid disorders), it is possible that the higher incidence of medical comorbidities among Qataris might have been influenced by the fact that they had significantly higher mean age than non-Qataris.

The rates of other medical comorbidities, such as dyslipidemia (9.8\%) and hypertension $(9.2 \%)$, in our study population were lower than those reported by Bener et al in the general population in Qatar (hypertriglyceridemia 27.9\% in men and $20.1 \%$ in women; hypertension $31.1 \%$ in men and $30.2 \%$ in women). ${ }^{28} \mathrm{We}$ also did not find high rates of cardiovascular disease in our cohort of outpatients with SMI. Heart disease typically manifests later in life, and it may be that the relative youth of our study population (mean age, 41.2 
years) did not allow us to observe what would be the predicted downstream effects of this high prevalence of cardiovascular risk factors. Nevertheless, there is substantial evidence that cardiovascular disease is a major contributor to the excess mortality seen in patients with SMI, which implicate modifiable cardiovascular risk factors that have also been found to

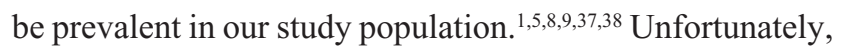
the lack of documentation on certain parameters (such as smoking status) prevented us also from estimating cardiovascular disease risk in our study population.

Thyroid abnormality was the fourth most prevalent comorbid condition documented among our study population. The prevalence of thyroid abnormalities in patients with BPAD was slightly lower $(4.9 \%)$ than in patients with schizophrenia $(6.8 \%)$ or MDD (5.5\%). Although the association between thyroid dysfunction (particularly hypothyroidism) and mood disorders is well recognized, such an association with psychotic disorders has not been as frequently reported. ${ }^{39}$ The lower prevalence among patients with mood disorder observed in our sample could be partially explained by the lack of documented laboratory parameters to check for thyroid abnormalities among people with mood disorders. Other common medical comorbidities that have been reported in other studies such as respiratory conditions, anemia and dermatological conditions were only minimally or not reported at all in our study. It is possible that these medical comorbidities were not observable in the selected study population during the 3-month data collection period, or because these conditions were being managed by primary care and thus not documented in the files of outpatients at the psychiatric clinic. Interestingly, we found no patients with cancer comorbidity. One possible way to explain this finding is that cancer patients in Qatar are followed up by the National Center for Cancer Care and Research. However, that information was not available in the psychiatric records of the patients that were included in this review.

Overall, there was an inadequate documentation of monitoring parameters for the medical comorbidities in our study population. Also, although the majority of our study population were on medications known to increase the risk for the development of medical comorbidities $(65.2 \%$ were on antipsychotics and $13.7 \%$ were on mood stabilizers), we were unable to estimate the incidence of obesity as the parameters to estimate body mass index, such as height and weight, were either not monitored or not documented in $98.5 \%$ and $73.2 \%$ of cases, respectively. There was also poor documentation or lack of follow-up of other important monitoring parameters that are recommended for patients who are treated with antipsychotics, such as serum prolactin levels, which was undocumented in $92.3 \%$ of this cohort of patients with SMI. Blood pressure, $\mathrm{HbA} 1 \mathrm{c}$, lipid profile and glucose monitoring were not monitored in $77.4 \%, 46.3 \%, 37.5 \%$ and $46.3 \%$ of our sample, respectively. Smoking status, an independent risk factor for the development of cardiovascular disease, was completely missed in the electronic charts of the patients in our study. These findings corroborate with existing literature that suggests inequitable medical care for patients with SMI. In a review of studies comparing the quality of medical care received by people with and without mental illness, Mitchell et al found that patients with psychiatric diagnoses received inferior quality of care in at least one medical area. ${ }^{40}$ In another study, which examined routine monitoring of patients taking antipsychotics, monitoring rates were generally low: lipids and HbA1c (<20\%), glucose (42\%), weight (44\%) and blood pressure $(67 \%) .{ }^{41}$

There are several points to be considered when interpreting our study results. As stated before, medical comorbidity was not consistently documented in the patients' electronic records and if documented, difficult to find as it was most often embedded within progress notes rather than in specific areas in the chart. As such, we retrieved medical diagnoses from the patients' medication history obtained from the last discharge history. This was the main reason why smoking history was not retrievable. This limitation will need to be addressed in future studies, possibly by utilizing other methodologies such as self-reported assessments, prospective assessments or interviews. Although the cohort may not be representative of the entire population of individuals with SMI, the results are of value as they provide some important observational and descriptive results not previously available in Qatar. However, these findings need to be confirmed by community-based studies utilizing more sophisticated methods that are more adequate in prevalence studies.

\section{Conclusion}

The study presented represents the first in Qatar to explore the prevalence rates of physical comorbidity in a cohort of individuals with SMI. Consistent with worldwide reports, this study confirms that in Qatar, individuals with SMI have a high prevalence of diabetes, which was highest among those with psychotic disorders. Although suggested by international monitoring guidelines, patients with SMI in Qatar, particularly those on antipsychotic medications, receive relatively low levels of medical and preventative care. Overall, poor documentation on physical comorbidities and relevant risk factors is prevalent in patients with SMI. Confirmation of 
these findings through prospective study designs, possibly comparing the prevalence of the comorbidities in SMI patients with the general population, is recommended.

\section{Acknowledgments}

This study was made possible by a UREP grant (UREP18060-3-016) for undergraduate research from the Qatar National Research Fund (a member of Qatar Foundation).

We extend our thanks to the staff at HMC, particularly at the psychiatric hospital, who helped us with data collection.

\section{Disclosure}

The authors report no conflicts of interest in this work.

\section{References}

1. DE Hert M, Correll CU, Bobes J, et al. Physical illness in patients with severe mental disorders. I. Prevalence, impact of medications and disparities in health care. World Psychiatry. 2011;10(1):52-77.

2. Walker ER, McGee RE, Druss BG. Mortality in mental disorders and global disease burden implications: a systematic review and metaanalysis. JAMA Psychiatry. 2015;72(4):334-341.

3. Schinnar AP, Rothbard AB, Kanter R, Jung YS. An empirical literature review of definitions of severe and persistent mental illness. Am J Psychiatry. 1990;147(12):1602-1608.

4. Saha S, Chant D, McGrath J. A systematic review of mortality in schizophrenia: is the differential mortality gap worsening over time? Arch Gen Psychiatry. 2007;64(10):1123-1131.

5. Colton CW, Manderscheid RW. Congruencies in increased mortality rates, years of potential life lost, and causes of death among public mental health clients in eight states. Prev Chronic Dis. 2006;3(2):A42.

6. Lawrence D, Hancock KJ, Kisely S. The gap in life expectancy from preventable physical illness in psychiatric patients in Western Australia: retrospective analysis of population based registers. $B M J$. 2013;346:f2539.

7. Dickerson FB, Brown CH, Daumit DL, et al. Health status of individuals with serious mental illness. Schizophr Bull. 2006;32(3):584-589.

8. Bresee LC, Majumdar SR, Patten SB, Johnson JA. Prevalence of cardiovascular risk factors and disease in people with schizophrenia: a population-based study. Schizophr Res. 2010;117(1):75-82.

9. Lesage A, Rochette L, Émond V, et al. A surveillance system to monitor excess mortality of people with mental illness in Canada. Can J Psychiatry. 2015;60(12):571-579.

10. Green AI, Patel JK, Goisman RM, Allison DB, Blackburn G. Weight gain from novel antipsychotic drugs: need for action. Gen Hosp Psychiatry. 2000;22(4):224-235.

11. Cohn T, Prud'homme D, Streiner D, Kameh H, Remington G. Characterizing coronary heart disease risk in chronic schizophrenia: high prevalence of the metabolic syndrome. Can J Psychiatry. 2004; 49(11):753-760.

12. Lawrence D, Kisely S. Inequalities in healthcare provision for people with severe mental illness. J Psychopharmacol. 2010;24(4 Suppl): 61-68.

13. Bauer MS, Williford WO, McBride L, McBride K, Shea NM. Perceived barriers to health care access in a treated population. Int $J$ Psychiatry Med. 2005;35(1):13-26.

14. Dunbar L, Brandt T, Wheeler A, Harrison J. Barriers and solutions to implementing metabolic risk assessment in a secondary mental health service. Australas Psychiatry. 2010;18(4):322-325.

15. Fagiolini A, Goracci A. The effects of undertreated chronic medical illnesses in patients with severe mental disorders. J Clin Psychiatry. 2009;70(Suppl 3):22-29.
16. Kisely S, Smith M, Lawrence D, Cox M, Campbell LA, Maaten S. Inequitable access for mentally ill patients to some medically necessary procedures. CMAJ. 2007;176(6):779-784.

17. Schulman-Marcus J, Goyal P, Swaminathan RV, et al. Comparison of trends in incidence, revascularization, and in-hospital mortality in ST-elevation myocardial infarction in patients with versus without severe mental illness. Am J Cardiol. 2016;117(9):1405-1410.

18. Lambert TJ, Newcomer JW. Are the cardiometabolic complications of schizophrenia still neglected? Barriers to care. Med J Aust. 2009; 190(4 Suppl):S39-S42.

19. De Hert M, Cohen D, Bobes J, et al. Physical illness in patients with severe mental disorders. II. Barriers to care, monitoring and treatment guidelines, plus recommendations at the system and individual level. World Psychiatry. 2011;10(2):138-151.

20. Rosenbaum L. Closing the mortality gap-mental illness and medical care. N Engl J Med. 2016;375(16):1585-1589.

21. Horvitz-Lennon M, Kilbourne AM, Pincus HA. From silos to bridges: meeting the general health care needs of adults with severe mental illnesses. Health Aff (Millwood). 2006;25(3):659-669.

22. Qatar National Mental Health Strategy. Changing Minds, Changing Lives 2013-2018. Doha, Qatar: General Secretariat, Supreme Council of Health; 2013.

23. American Psychiatric Association. Diagnostic and Statistical Manual of Mental Disorders: DSM-IV [Internet]. 4th ed. Washington, DC: American Psychiatric Association; 1994.

24. Gearing RE, Mian IA, Barber J, Ickowicz A. A methodology for conducting retrospective chart review research in child and adolescent psychiatry. J Can Acad Child Adolesc Psychiatry. 2006;15(3): 126-134.

25. Singh GP, Chavan BS, Kaur P, Bhatia S. Physical illnesses among psychiatric outpatients in a tertiary care health institution: a prospective study. Indian J Psychiatry. 2006;48(1):52-55.

26. Manuel CM, Rao PP, Rebello P, Safeekh AT, Mathai PJ. Medical comorbidity in in-patients with psychiatric disorder. Muller J Med Sci Res. 2013;4(1):12-17.

27. Bener A, Zirie M, Janahi IM, Al-Hamaq AO, Musallam M, Wareham NJ. Prevalence of diagnosed and undiagnosed diabetes mellitus and its risk factors in a population-based study of Qatar. Diabetes Res Clin Pract. 2009;84(1):99-106.

28. Bener A, Al-Suwaidi J, Al-Jaber K, Al-Marri S, Dagash MH, Elbagi IE. The prevalence of hypertension and its associated risk factors in a newly developed country. Saudi Med J. 2004;25(7):918-922.

29. Musallam M, Bener A, Zirie M, et al. Metabolic syndrome and its components among Qatari population. Int J Food Saf Nutr Publ Health. 2008;1(1):88-102.

30. Aljefree N, Ahmed F. Prevalence of cardiovascular disease and associated risk factors among adult population in the Gulf region: a systematic review. Adv Public Health. 2015;2015: Article ID 235101.

31. Sokal J, Messias E, Dickerson FB, et al. Comorbidity of medical illnesses among adults with serious mental illness who are receiving community psychiatric services. J Nerv Ment Dis. 2001;192(6):421-427.

32. Kronick RG, Bella M, Gilmer TP. The Faces of Medicaid III: Refining the Portrait of People with Multiple Chronic Conditions. Hamilton, NJ: Center for Health Care Strategies, Inc.; 2009.

33. Dixon L, Weiden P, Delahanty J, et al. Prevalence and correlates of diabetes in national schizophrenia samples. Schizophr Bull. 2000;26(4): 903-912.

34. Bushe C, Holt R. Prevalence of diabetes and impaired glucose tolerance in patients with schizophrenia. Br J Psychiatry Suppl. 2004;47: S67-S71.

35. De Hert M, van Winkel R, Van Eyck D, et al. Prevalence of diabetes, metabolic syndrome and metabolic abnormalities in schizophrenia over the course of the illness: a cross-sectional study. Clin Pract Epidemiol Ment Health. 2006;2:14.

36. Ford ES, Giles WH, Dietz WH. Prevalence of the metabolic syndrome among US adults: findings from the third National Health and Nutrition Examination Survey. JAMA. 2002;287(3):356-359. 
37. Olfson M, Gerhard T, Huang C, Crystal S, Stroup TS. Premature mortality among adults with schizophrenia in the United States. JAMA Psychiatry. 2015;72(12):1172-1181.

38. Osborn DP, Levy G, Nazareth I, Petersen I, Islam A, King MB. Relative risk of cardiovascular and cancer mortality in people with severe mental illness from the United Kingdom's General Practice Research Database. Arch Gen Psychiatry. 2007;64(2):242-249.

39. Hennessey JV, Jackson IM. The interface between thyroid hormones and psychiatry. Endocrinologist. 1996;6:214-223.
40. Mitchell AJ, Malone D, Doebbeling CC. Quality of medical care for people with and without comorbid mental illness and substance misuse: systematic review of comparative studies. Br J Psychiatry. 2009;194(6): 491-499.

41. Mitchell AJ, Delaffon V, Vancampfort D, Correll CU, De Hert M. Guideline concordant monitoring of metabolic risk in people treated with antipsychotic medication: systematic review and meta-analysis of screening practices. Psychol Med. 2012;42(1):125-147.

\section{Publish your work in this journal}

Neuropsychiatric Disease and Treatment is an international, peerreviewed journal of clinical therapeutics and pharmacology focusing on concise rapid reporting of clinical or pre-clinical studies on a range of neuropsychiatric and neurological disorders. This journal is indexed on PubMed Central, the 'PsycINFO' database and CAS, and is the official journal of The International Neuropsychiatric Association (INA). The manuscript management system is completely online and includes a very quick and fair peer-review system, which is all easy to use. Visit http://www.dovepress.com/testimonials.php to read real quotes from published authors.

Submit your manuscript here: http://www.dovepress.com/neuropsychiatric-disease-and-treatment-journal 